\title{
Correspondence
}

\section{Correcting a block?: successful experience of a small British pacing centre}

Sir,

I am concerned that the report by Dr Godden and his colleagues of a small British pacing centre (1987;58:495-8) which describes the exclusive use of single chamber demand (VVI) pacing does not justify its conclusion that the mode "is the system of choice for most elderly sedentary patients", especially as a considerable proportion of patients were suffering from breathlessness and tiredness, for which physiological pacing modes have been shown to be superior. ${ }^{12}$ Their patients' average age was 74 -little older than those in other published series.

Age is no bar to the optimum treatment of tiredness and breathlessness. We are given no information about the distribution of tiredness and none on the frequency of breathlessness, except when it is the major symptom. Even more unsatisfactory in their report is the syphoning off of patients to other centres if a "more complex system was required"; there is no indication of numbers, reasons, or ages and this feature must negate their conclusion about the use of VVI pacing. Also of concern is their decision to use VVI pacing in sinus node disease (no information on how many patients) despite its well documented inferiority and association with several complications. ${ }^{34}$

Finally, we are given extremely limited information about the investigation undertaken to arrive at the choice of pacing mode. We are told (in the discussion and not in the methods or results) that 24 hour ambulatory monitoring was undertaken in 37 out of 100 and that it influenced the decision. We do not know what it showed, how it influenced the decision, or whether it influenced decisions on how to pace. What about the use of simple electrophysiology, trial of pacing, exercise testing, etc? If one is seeking to improve symptoms other than syncope or presyncope some or all of these investigations are often required if patients are to get the best treatment. There might even be a cost advantage in the long run in using a more expensive pacemaker with less medication.
Simon Joseph,

Cardiac Department, Mayday Hospital, Thornton Heath, Surrey CR4 7YE

References

1 Kristensson B-E, Arnman K, Smedgard P, Ryden L., Physiological versus single rate ventricular pacing: $a_{\overrightarrow{0}}$ double-blind cross-over study. PACE 1985;8:73-84.

2 Boon NA, Frew AJ, Johnston JA, Cobbe SM. A. comparison of symptoms and intra-arterial blood pressure during long term dual chamber atrioventricular synchronous (DDD) and ventricular demand (VVI) pacing. Br Heart J 1987;58:34-9.

3 Rosenqvist M, Brandt J, Schuller $H$. Atrial versus ventricular pacing in sinus node disease: a treatment comparison study. Am Heart J 1986;111:292-7.

4 Curzi GF, Massacci C, Breccia Fratadocci G, Mocchegiani R, Berrettini U, Purcaro A. Thromboembolism in paced patients [Abstract]. PACE 1987; 10:662.

This letter was shown to one of the authors, who replies as follows:

Sir,

I thank Dr Joseph for his comments. Regrettably he misquotes our paper. The statement "VVI pacing probably remains the system of choice for moss elderly patients" was not the conclusion of our paperㅡㅡ. We attempted to show that a pacing centre in as district general hospital increases the implant rate in the area served by the hospital. The comment on suitability of VVI pacing for the sedentary elderly was clearly attributed to another author. ${ }^{1}$ Our stud可 was not designed to assess the efficacy of differeno pacing modes.

I can reassure Dr Joseph that "syphoning off" of patients to specialist centres for more complex pacing

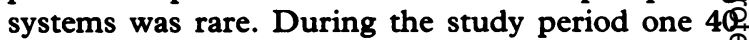
year old man was referred to be considered for dua\$ chamber pacing and received a single electrode rat responsive system. A 70 year old woman required 